\title{
Reflow Residues on Printed Circuit Board Assemblies and Interaction with Humidity
}

\author{
Conseil-Gudla, Helene; Li, Feng; Ambat, Rajan
}

Published in:

IEEE Transactions on Device and Materials Reliability

Link to article, DOI:

10.1109/TDMR.2021.3120941

Publication date:

2021

Document Version

Peer reviewed version

Link back to DTU Orbit

Citation (APA):

Conseil-Gudla, H., Li, F., \& Ambat, R. (2021). Reflow Residues on Printed Circuit Board Assemblies and Interaction with Humidity. IEEE Transactions on Device and Materials Reliability, 21(4), 594-602.

https://doi.org/10.1109/TDMR.2021.3120941

\section{General rights}

Copyright and moral rights for the publications made accessible in the public portal are retained by the authors and/or other copyright owners and it is a condition of accessing publications that users recognise and abide by the legal requirements associated with these rights.

- Users may download and print one copy of any publication from the public portal for the purpose of private study or research.

- You may not further distribute the material or use it for any profit-making activity or commercial gain

- You may freely distribute the URL identifying the publication in the public portal

If you believe that this document breaches copyright please contact us providing details, and we will remove access to the work immediately and investigate your claim. 


\title{
Reflow Residues on Printed Circuit Board Assemblies and Interaction with Humidity
}

\author{
Helene Conseil-Gudla, Feng Li and Rajan Ambat
}

\begin{abstract}
Ionic residues resulting from the soldering process is an important parameter in connection with humidity robustness of Printed Circuit Board Assemblies (PCBAs) due to their ability to enhance moisture absorption and surface conductivity. For reflow process, residues are trapped under the components, and the morphology of the residues can change with humidity exposure resulting in the release of ionic components.

In this work, trapped residues below the components from reflow process of several commercial PCBAs were characterized before and after exposure to humidity conditions. PCBAs used for the analysis had undergone multiple reflow heating profiles by single and double reflow plus additional passes to understand heating effects.

The morphology change of the trapped residues under components upon humidity exposure was observed using optical and scanning electron microscopy. The conductivity of the localized extracted solutions was measured and $\mathrm{NaCl}$ equivalency was determined. The solder paste materials were analysed for their water sorption property, while the effect of humidity on electrical property was assessed using electrochemical impedance spectroscopy using test PCBs.

The results show that the change in morphology and level of activator release of residues were a function of the flux type, PCBA characteristics such as component standoff height and number of reflow cycles. Water layer formation upon humidity exposure and electrical properties on test PCBs are correlated with water sorption of the flux part.
\end{abstract}

Index Terms-Board, Components, Conductivity, Humidity, Reflow, Standoff height, Trapped residues, Water absorption.

\section{INTRODUCTION}

SOLDER paste (SP) printing and reflow soldering are standard $N_{\text {processes used for manufacturing surface mount }}$ assemblies. The SP is applied using a stencil printing followed by the mounting of surface mount device (SMD) components. The PCBAs then pass through a soldering oven and experience a pre-heat zone (allowing the outgassing of any volatile compounds of the SP), a soaking zone (allowing the activation of the flux), followed by a reflow zone where a peak temperature between 230 and $250^{\circ} \mathrm{C}$ is reached, which will solder the SMD, followed by a cooling phase.

In the reflow soldering process, many factors can affect the soldering quality and cleanliness level of PCBAs: At process method level, such as (i) the application method (stencil), (ii)

*Copyright (C) 2021 (or current year) IEEE. Personal use of this material is permitted. However, permission to use this material for any other purposes must be obtained by sending a request to pubs-permissions@ieee.org the reflow temperature profile, (iii) the temperature uniformity in the oven, (iv) the line speed and (v) the number of step operation (single or double reflow). At PCBAs design level, such as (i) amount of copper within the PCB, (ii) the number of SMD, (iii) the geometry and size of the SMD and its contact pads, and (iv) the type of the SP and their melting points [1]. The tin-silver-copper (SAC) alloys have a higher melting temperature (about $220^{\circ} \mathrm{C}$ ) than the traditional leaded solders (about $183^{\circ} \mathrm{C}$ ). Therefore, the reflow thermal profile requires optimization to avoid excessive temperatures for the SMD and the laminate boards.

The no-clean flux chemistry used in SAC SP is designed to minimize issues associated with higher reflow temperatures, such as increased paste slump and residue charring [2]. The information of the exact chemistry of SP is confidential and unlikely to be released by any paste manufacturer. Nevertheless, the main composition of SP [3] is a mixture of a metal alloy powder (about 90 w. \%) and a resin-based flux, such as rosins, and/or resins. Activators, such as halides (chlorides, bromides), weak organic acids (WOAs), organic amines, or halogen-containing compounds, remove any oxide film present from metallic surfaces. Solvents, such as glycol or poly-alcohol, ensure a good solubility of the flux, and a good electric insulation resistance during the melting of the SP. Thixotropic agents, and other additives such as antioxidants, rust-preventing agents, and chelating agents can also be part of the flux composition.

Unlike for wave soldering process, no-clean flux residues from reflow process exist on the PCBA surface as localized residues under the components due to the application process. The amount of flux applied in the reflow process is specific to the component footprint areas, therefore trapped residues can be found under components [4-6]. After soldering, the acidic compounds of the SP are concealed within/underneath the filmformer layer (unevaporated resin). However, upon humidity exposure, the appearance and morphology of the film-former can change [7]. Deterioration of the film-former results in release of active compounds such as WOAs below the SMD [6]. WOAs are hygroscopic and tend to absorb moisture from the surrounding environment. The formed water film is saturated with ions, and located below the SMD. The conductive and occluded water film can lead to the reduction of surface insulation resistance (SIR) between the biased pads,

The authors are with the Department of Mechanical Engineering, Technical University of Denmark, Lyngby 2800, Denmark (e-mail: helco@mek.dtu.dk). 
high leak current, and likely to electrochemical migration (ECM), which can lead to premature failure of the devices [811]. A large amount of literature can be found on the impact of process-related flux contamination on the electronics reliability, but focus is done on wave solder flux systems and WOAs [821]. Only few investigations were done on reflow residues [6$7 ; 22]$, as the amount of contamination is believed to be very low and benign.

The investigations in this paper aim to characterize the localized reflow residue below components as a function of the component standoff, flux chemistry, and process conditions such as the number of reflow profile exposure. Analyzed PCBAs were directly taken from the manufacturing line and correspond to different applications. They are then analyzed for profiling the reflow residue chemistry. A set of PCBAs were investigated, which have undergone different steps of soldering processes, such as single reflow (SMT1), double reflow (SMT2), and double reflow plus selective wave soldering process (SWS). Additionally two PCBAs were exposed to 9 reflow heating profiles for understanding the effect on residue (SMT4, 5, 8 and 9). Trapped residues below the components as a function of the standoff height was analyzed. Morphology of the residue was analyzed under optical microscope on asreceived $\mathrm{PCBA}$ and after exposure to humidity (at $98 \% \mathrm{RH}$ and $40^{\circ} \mathrm{C}$ or $60^{\circ} \mathrm{C}$ for 7 days) by removing the components. Localized extractions were performed, and residue levels quantified using conductivity measurements. For comparison, two different SPs used for the manufacturing of the PCBAs used for this investigation were analyzed for water absorption behaviour, change in chemistry upon humidity exposure, and effect on corrosion reliability using test PCBs reflowed using the SP.

\section{MATERIALS AND METHOD}

\section{A. PCBAs used for investigations and analysis methods}

\section{1) Printed Circuit Board Assemblies}

A set of industrially processed PCBAs (from 3 manufacturers) soldered by multiple passes namely top side by reflow (SMT1), further soldering of the components on the bottom side by reflow (SMT2), and the soldering of added components on the top side by selective wave soldering (SWS) was investigated. Additionally, two PCBA types were also processed through multiple reflow heating profiles up to 3 and 7 additional passing. Table 1 shows the notation of the SP used for soldering PCBAs, and various heating steps and corresponding notation to identify the PCBAs. As shown in Table 1, manufacturer 1 used solder paste SPa, while manufacturers 2 and 3 used $\mathrm{SPb}$. The solder alloy composition was similar for both. Flux part was different, however both are based on organic film-former with low level of activator in the flux (ORLO).

Various SMDs (leaded components) of different dimensions were selected on all PCBAs, and their related standoff height was measured using feeler gauges, consisting of 19 blades with a thickness range from 0.04 to $1 \mathrm{~mm}$ (Facom 804P). The measured standoff heights were in the range $0.04 \mathrm{~mm}$ to 1.6 $\mathrm{mm}$.

TABLE I

PRINTED CIRCUIT BOARD ASSEMBLIES CHARACTERISTICS

\begin{tabular}{|c|c|c|c|}
\hline $\begin{array}{l}\text { Manufa } \\
\text { cturer }\end{array}$ & $\begin{array}{l}\text { Dimension } \\
\quad(\mathrm{mm})\end{array}$ & $\begin{array}{c}\text { Type of } \\
\text { solder paste }\end{array}$ & $\begin{array}{c}\text { Soldering step operation of } \\
\text { PCBA }\end{array}$ \\
\hline 1 & $\begin{array}{c}105 * 275 \\
140 * 140 \\
60 * 128\end{array}$ & SPa* & $\begin{array}{l}\text { SMT1, SMT2, SWS } \\
2 \text { additional PCBAs: SMT1, } \\
\text { SMT2, SMT4, SMT5, } \\
\text { SMT8, SMT9 }\end{array}$ \\
\hline 2 & $80 * 85$ & $\mathrm{SPb}^{* *}$ & SMT1, SMT2, SWS \\
\hline 3 & $85 * 113$ & $\mathrm{SPb}^{* *}$ & SMT1, SMT2, SWS \\
\hline
\end{tabular}

*SPa: Solder alloy (Sn96.5-Ag3.0-Cu0.5) - Solder flux: 9.4 w.\% solid content

**SPb: Solder alloy (Sn96.5-Ag3.0-Cu0.5) - Solder flux: 13.1 w.\% solid content

\section{2) Climatic exposure and residues analysis}

The PCBAs were analyzed as-received, and after exposure to $40^{\circ} \mathrm{C} / 98 \% \mathrm{RH} / 7$ days and $60^{\circ} \mathrm{C} / 98 \% \mathrm{RH} / 7$ days in a climatic chamber (Espec, Escorp PL-3KPH). The temperature and humidity fluctuations for the climatic chamber were stated to be within $\pm 0.3^{\circ} \mathrm{C}$ (under $-40^{\circ} \mathrm{C}$ to $100^{\circ} \mathrm{C}$ ) and $\pm 3.0 \% \mathrm{RH}$. After the climatic exposure, the selected SMD were removed using a cutting tool (Dremel 300 series). The morphology of the residues under the SMD (on as-received PCBAs and after exposure) was then observed, using an optical microscope (OM) (Keyence, VHX-6000 series) and a scanning electron microscope (SEM) (Model Quanta 200 ESEM FEG, FEI) at an acceleration voltage of $3 \mathrm{kV}$. The morphology of the residues under a large number of SMD components was observed by $\mathrm{OM}$, one location has been selected as a good representation of the morphology of the residues for each manufacturer's PCBA, and the associated SEM picture was performed.

\section{3) Localized extraction of residue and conductivity measurement}

Rings with an inner diameter of $0.79 \mathrm{~cm}^{2}$ were placed on the selected areas of the PCBAs (where the SMD were removed). A volume of $200 \mu \mathrm{L}$ of ultrapure water was poured inside the ring and a soaking time of $3 \mathrm{~min}$ allowed the ionic residues to dissolve into the water, after which the solution was collected via a syringe. The conductivity of the solutions was measured using a benchtop S230 SevenCompact ${ }^{\mathrm{TM}}$ conductivity meter (Mettler Toledo). A calibration curve obtained with different concentrations of $\mathrm{NaCl}$ solutions was used to estimate the localized $\mathrm{NaCl}$ equivalent concentration under the components.

\section{B. Solder pastes characterization}

1) Water absorption behavior of the flux part

$\mathrm{SPa}$ and $\mathrm{SPb}$ were placed into an aluminium cup and subjected to a simulated reflow soldering process (Techno- HA06, Technoprint), with a pre-heat at $210{ }^{\circ} \mathrm{C}$ for $120 \mathrm{~s}$ and a reflow at $270{ }^{\circ} \mathrm{C}$ for $60 \mathrm{~s}$. This resulted in a phase separation of the metallic part and the liquid part (flux and organic filmformer) of the SP. The liquid part was then poured into a glass Petri dish, and was placed inside a moisture sorption analyser (Vsorb, ProUmid) under a controlled environment of $25^{\circ} \mathrm{C}$ and $95 \%$ RH. Gravimetric measurements were performed 
periodically until moisture saturation. The final water uptake $X_{\infty}$, which corresponds to the saturated amount of water absorbed by the flux, was calculated using the equation:

$$
X_{\infty}=\frac{\Delta m \infty}{m_{0}} .100
$$

Where $X_{\infty}[\mathrm{wt} . \%]$ is the saturated moisture uptake, $m_{0}[\mathrm{~g}]$ is the initial dry weight of the sample and $\Delta m \infty$ is the saturated change of weight of the sample $[\mathrm{g}]$ upon exposure.

\section{2) Effect of reflow chemistry on electronic reliability}

\section{a) Test boards preparation}

Two types of test structures were used for humidity testing of the SP: (i) an interdigitated SIR comb structure (Fig. 1.a) and (ii) a test PCB with 9 solder pads with a part acting as the PCB substrate and a part with equal number of pads (Fig. 1.b1) mimicking a component when placed on top of the PCB pad as shown in Fig. 1.b2, referred as dummy component test PCB. The base material of the test specimens is lead-free Sn100C alloy with HASL surface finish. The dimensions of the test pattern of the SIR test PCB are $13 \mathrm{~mm} \times 25 \mathrm{~mm}$ area and 0.3 $\mathrm{mm}$ pitch distance between electrodes (Fig. 1.a). The distance between the nine solder pads (Fig. 1.b1) is $3 \mathrm{~mm}$ and the standoff height used for dummy component test PCB is $1 \mathrm{~mm}$. After the soldering process, for electrical measurements during humidity exposure, two adjacent pads where electrically connected from the backsides of the test PCB set-up, as shown Fig. 1.b3.

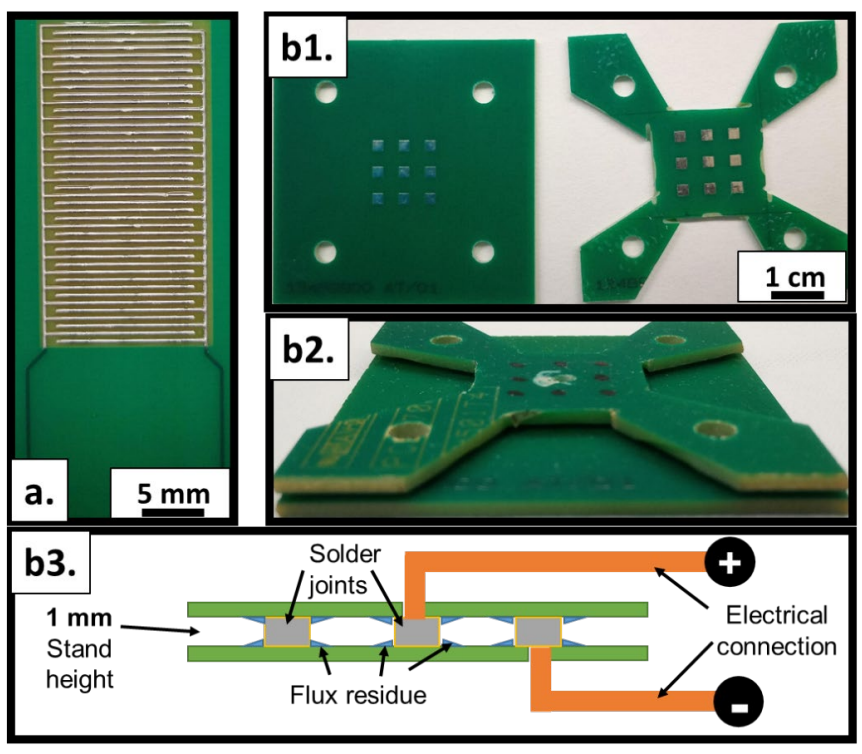

Fig. 1. Picture of test PCBs used in this investigation: a) SIR test PCB, and b1) nine pads PCB base and top parts, b2) assembled 9 pads PCB as a dummy component, and b3) schematic showing the side view of the dummy component test PCB set up with the electrical connections.

Prior to the soldering, the test PCBs were cleaned by rinsing with deionized water and with isopropyl alcohol. The molten SP were then transferred from a stencil aperture to the test PCBs (SIR pattern and nine solder pads PCBs as required). For nine pads $\mathrm{PCB}$, the top part was joined by introducing washers between to adjust the gap to $1 \mathrm{~mm}$. The test PCBs were then subjected to a simulated reflow soldering process (Techno- HA06 , Technoprint). The surface temperature of the test PCBs was measured (Extech SDL200 4-Channel Datalogging Thermometer) and the reflow profile temperature experienced by the test PCB surface during the pre-heat for $120 \mathrm{~s}$ was about $25-160{ }^{\circ} \mathrm{C}$, followed by the reflow for $60 \mathrm{~s} 160-238{ }^{\circ} \mathrm{C}$, and reached the peak reflow temperature of $245^{\circ} \mathrm{C}$ within $60 \mathrm{~s}$. The test PCBs were then cooled in air temperature and the electrical connections were performed.

b) Residue quantification on PCBs and electrical testing

Prior to the test, the flux residue on the SIR PCB was extracted and analyzed for conductivity using the method described in section II.A.3. Residues level was analyzed after the reflow operation, and after exposure to $40^{\circ} \mathrm{C} / 98 \% \mathrm{RH} / 7$ days and $60^{\circ} \mathrm{C} / 98 \% \mathrm{RH} / 7$ days, for comparison with the $\mathrm{NaCl}$ eq concentration measured on the manufactured PCBAs.

The reflowed SIR and dummy component test PCBs were then exposed to $60^{\circ} \mathrm{C} / 98 \% \mathrm{RH}$ in a climatic chamber (Espec, Escorp ARL-0680). Electrochemical impedance spectroscopy (EIS) measurement was performed over a period of 7 days, after one hour exposure, followed with a $24 \mathrm{~h}$ sweep time during 7 days, with a signal amplitude of $10 \mathrm{mV}$ over a frequency range of 100 $\mathrm{kHz}$ to $100 \mathrm{mHz}$ (Biologic VSP-series potentiostat system). The morphology change of the residues on test PCBs after humidity exposure was then observed by OM.

\section{RESULTS}

\section{A. Analysis of residue under components before and after exposure to humidity \\ 1) Morphology of residue before and after exposure to humidity}

Fig. 2 shows the typical reflow residues morphology under one component from each manufactured PCBAs. Pictures corresponding to as received materials (series 1) showed minor difference in residues morphology. While the PCBA soldered using SPa showed only minor changes to the morphology after exposure to humidity, the $\mathrm{SPb}$ soldered PCBAs showed significant change and clear spreading of the residue (series 2 and 3). Exposure to higher temperature showed higher change in morphology due to higher water content in the system. For $\mathrm{SPb}$ soldered PCBAs, high level of spreading led to connection between adjacent pads (showed by red arrows in Fig. 2).

PCBAs passed through additional reflow profiles were tested in a similar manner (Table 1). However, additional passes did not show significant difference in appearance of the residue, therefore not shown. Morphology shows slight reduction in the residue level with multiple reflow passes, however relative 
a.1

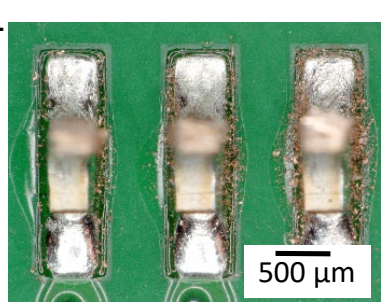

b.1

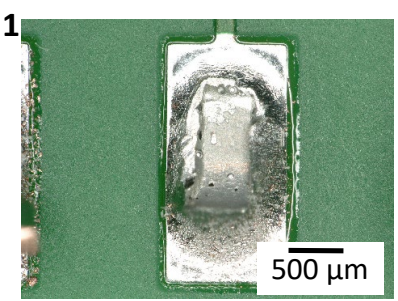

C.1

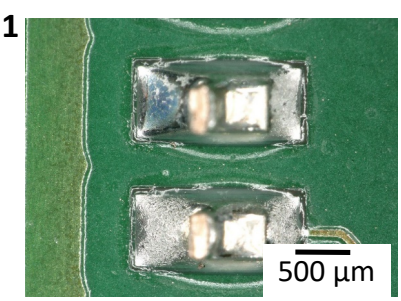

a.2

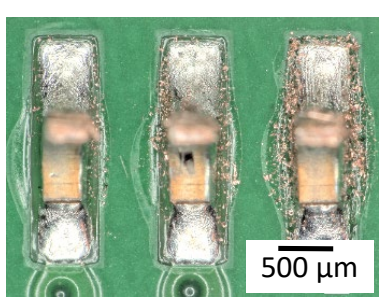

b. 2

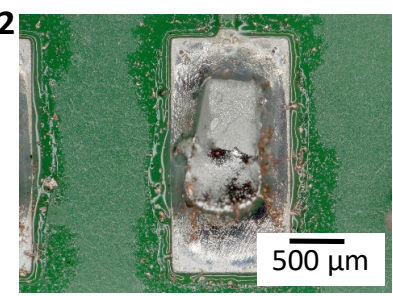

c. 2

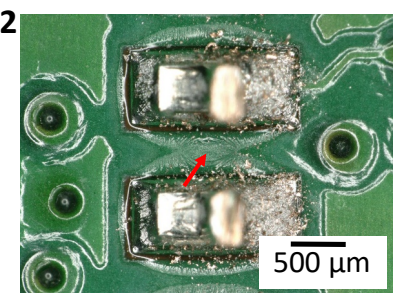

a.3

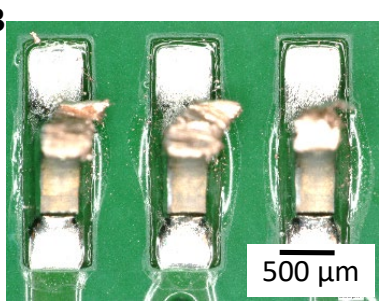

b.3

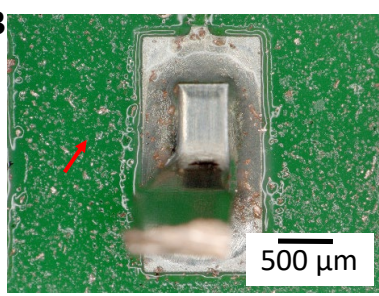

c.3

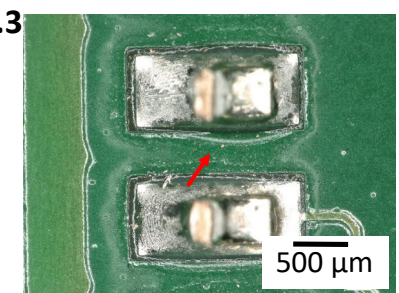

Fig. 2. OM pictures of the residue under a removed component (capacitor type) after SMT1: Series (a) - PCBA soldered using SPa and Series (b) and (c) - soldered using $\mathrm{SPb}$. (1) - as received, and after exposure to (2) $-40^{\circ} \mathrm{C} / 98 \% \mathrm{RH} / 7$ days and (3) $-60^{\circ} \mathrm{C} / 98 \% \mathrm{RH} / 7$ days .

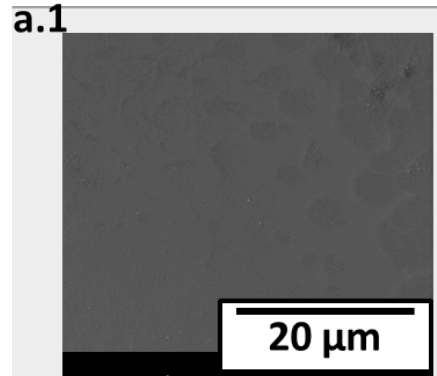

b.1

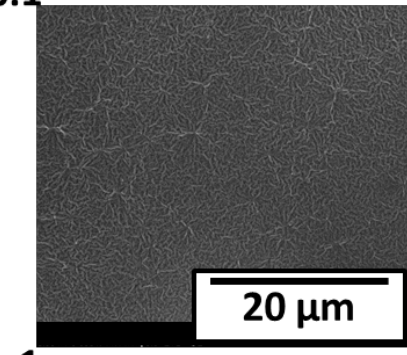

c.1

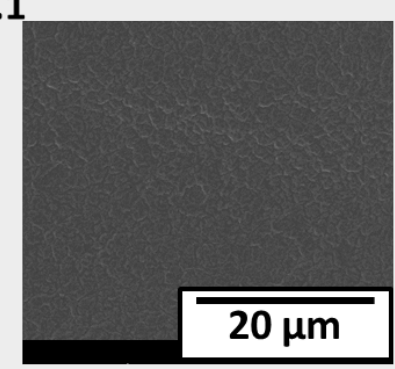

a.2

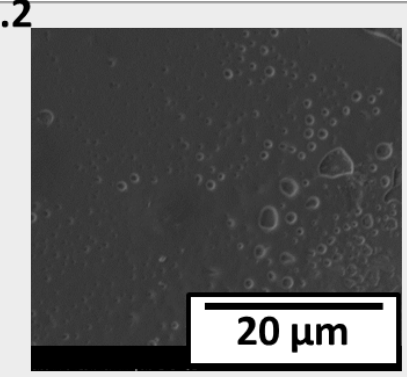

b. 2

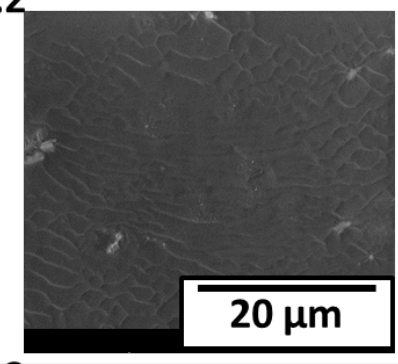

c. 2

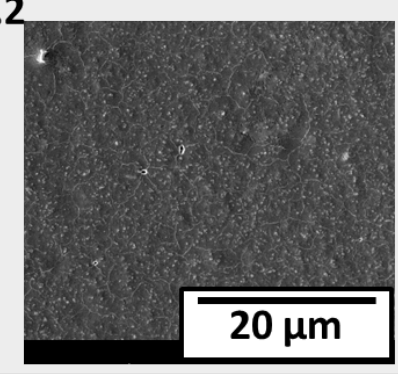

a.3

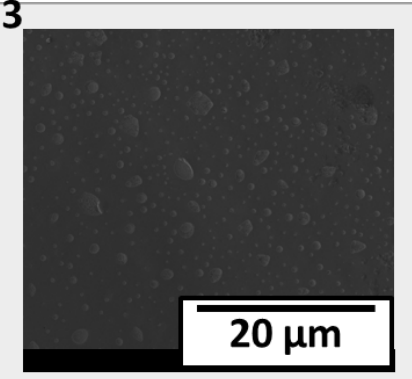

b.3

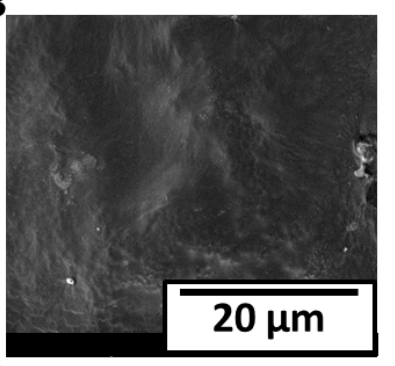

c.3

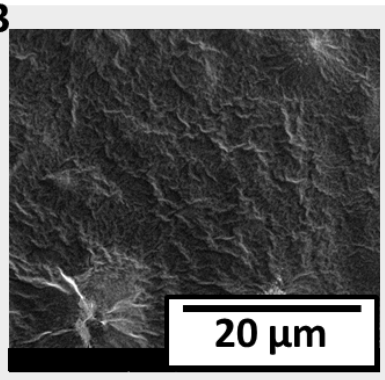

Fig. 3. SEM images of the residue under a removed component (capacitor type): Series (a) - PCBA soldered using SPa and Series (b) and (c) - soldered using SPb (1) - PCBA with SMT1 as received, and (2) - after exposure to $60^{\circ} \mathrm{C} / 98 \% \mathrm{RH} / 7$ days, (3) - PCBA with SWS process after exposure to $60^{\circ} \mathrm{C} / 98 \% \mathrm{RH} / 7$ days.

difference between PCBAs remained similar.

Fig. 3 shows the SEM images of the SP residues on same pads shown in Fig. 2. In correlation with the OM in Fig. 2, SEM pictures of SPa soldered PCBA before humidity exposure showed smooth morphology (Fig. 3.a1), while the SPb solder pads showed rough morphology resembling cracks in the 
residue film (Fig. 3.b1 and 3.c1). After exposure to humidity, $\mathrm{SPa}$ soldered pads showed only some blisters, while $\mathrm{SPb}$ soldered pads showed increased cracking, which further increased after additional reflow and selective wave soldering process (series 3 ).

\section{2) Quantification of contamination using local extraction}

On each PCBA, residues were extracted from underneath the selected components (after removal) in the received condition as well as after exposure at $40^{\circ} \mathrm{C} / 98 \% \mathrm{RH} / 7$ days and $60^{\circ} \mathrm{C} / 98 \% \mathrm{RH} / 7$ days. Fig. 4 shows the values in terms of $\mathrm{NaCl}$ equivalent (based on IPC standard IPC J-STD-001D). Values reported in Fig. 4 are averages of the analysis of many components on each board. PCBAs from manufacturer 1 soldered using SPa showed lower residue levels, and levels increased only marginally after exposure to humidity. PCBAs from manufacturer 2 and 3 soldered using $\mathrm{SPb}$ showed low levels under as-received condition, however after exposure to humidity, ionic residue levels in the extract increased. Although, both PCBAs were soldered using $\mathrm{SPb}$, some difference in residue levels was observed between manufacturers 2 and 3 , which might be due to the difference in components analyzed on both PCBAs as the designs were not same. Slight decrease of contamination levels can be observed for SMT2 compared to SMT1, while the levels after SWS are similar to SMT1.

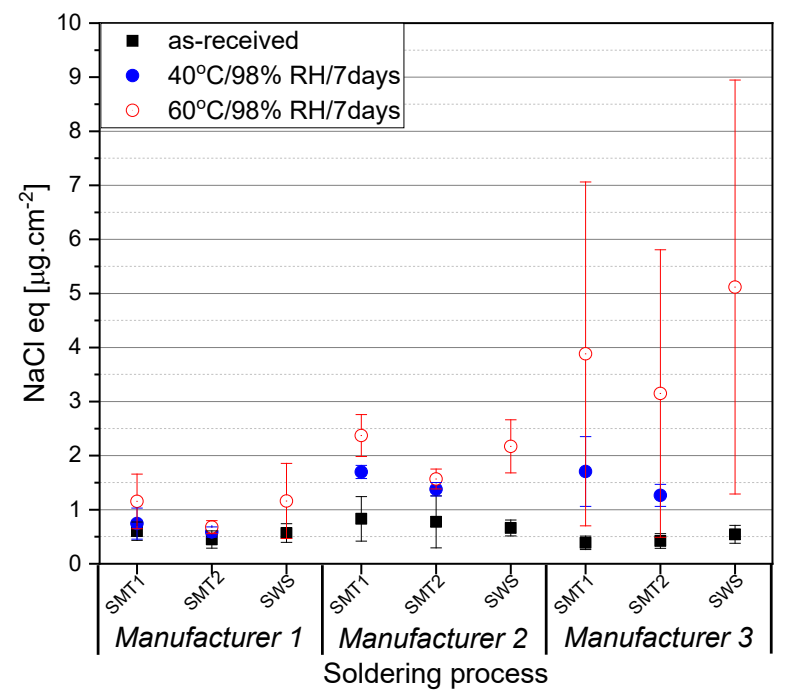

Fig. 4. Average of $\mathrm{NaCl}$ equivalent concentration of the localized residue under the SMDs of the PCBAs soldered with different soldering operation steps.

Fig. 5 shows the average results of $\mathrm{NaCl}$ equivalent of the extracts from 2 PCBAs from manufacturer 1 , which have undergone additional reflow step operations (Table 1). The PCBAs (SMT1 and SMT2 respectively for the top and bottom sides) were exposed to 3 and 7 more reflow operations. Many components from both sides of the PCBAs were removed and the residue levels were quantified before and after exposure to humidity. The analyzed components on both sides are different, therefore the general trend should be analyzed rather than the exact values. The results show a general decrease of residues after additional reflow steps, and it is more accentuated after

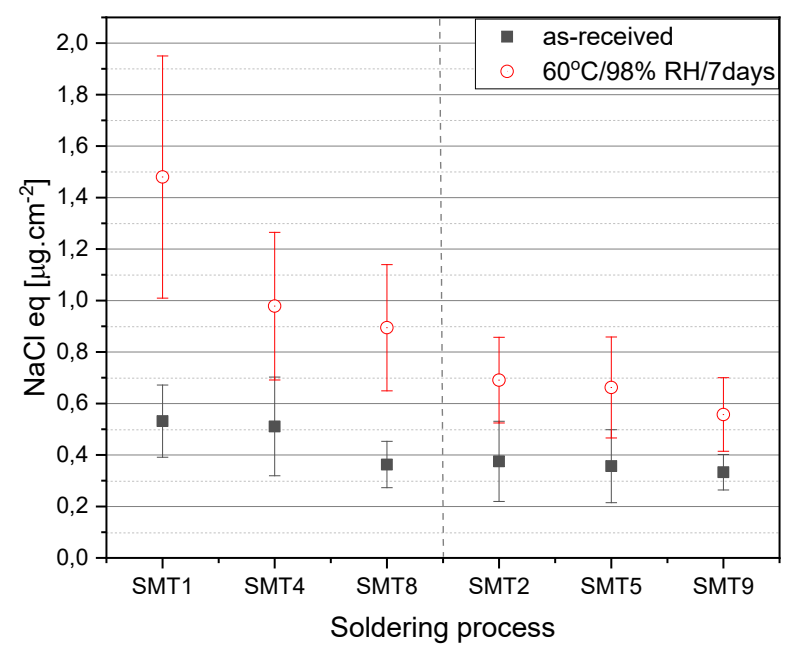

Fig. 5. Average of $\mathrm{NaCl}$ equivalent concentration of the localized residue under SMDs of the PCBAs from manufacturer 1, with additional reflow passes.

exposure to $60^{\circ} \mathrm{C} / 98 \% \mathrm{RH}$ for 7 days.

Fig. 6 shows the relationship between the standoff height of the SMD and $\mathrm{NaCl}$ equivalent concentration, for the PCBAs from manufacturer 1 (Fig. 6.a) and manufacturer 3 (Fig. 6.b). Number of SMD from manufacturer 2 PCBA being fewer, this PCBA has not been used for this analysis. The results show that upon moisture exposure, the conductivity of the residues under SMD with a low standoff height $(<100 \mu \mathrm{m})$ is higher than the ones under higher standoff height SMD.

\section{B. Solder pastes characterization}

\section{1) Water absorption}

Water absorption measurement of the flux part of the SP showed that $\mathrm{SPa}$ and $\mathrm{SPb}$ can absorb up to 1.6 w. $\% \pm 0.1$ and 7.7 w. $\% \pm 0.3$ of water at $25^{\circ} \mathrm{C} / 95 \% \mathrm{RH}$ respectively. Due to the limitations of the instrument, the tests have not been performed at higher temperatures; however, the relative difference observed at $25^{\circ} \mathrm{C}$ shows the higher affinity of $\mathrm{SPb}$ to absorb water, and therefore reflects the higher hygroscopic nature of the $\mathrm{SPb}$ residue on those manufactured PCBAs.

\section{2) Conductivity measurement on SIR test PCBS}

The conductivity of the extracts taken on SIR test PCBs reflowed with $\mathrm{SPa}$ and $\mathrm{SPb}$, before and after exposure to humidity was assessed using the same procedure than for the manufactured PCBAs. Results show that that the behavior of both flux pastes on SIR reflowed pattern is similar to that observed on the manufactured PCBAs, with $\mathrm{NaCl}$ equivalent values about 0.1. 0.4 and $2 \mu \mathrm{g} \cdot \mathrm{cm}^{-2}$ for $\mathrm{SPa}$ and about 0.3, 2.0 and $9.0 \mu \mathrm{g} \cdot \mathrm{cm}^{-2}$ for $\mathrm{SPb}$, before and after exposure to $40^{\circ} \mathrm{C} / 98 \% \mathrm{RH} / 7$ days and $60^{\circ} \mathrm{C} / 98 \% \mathrm{RH} / 7$ days respectively. 

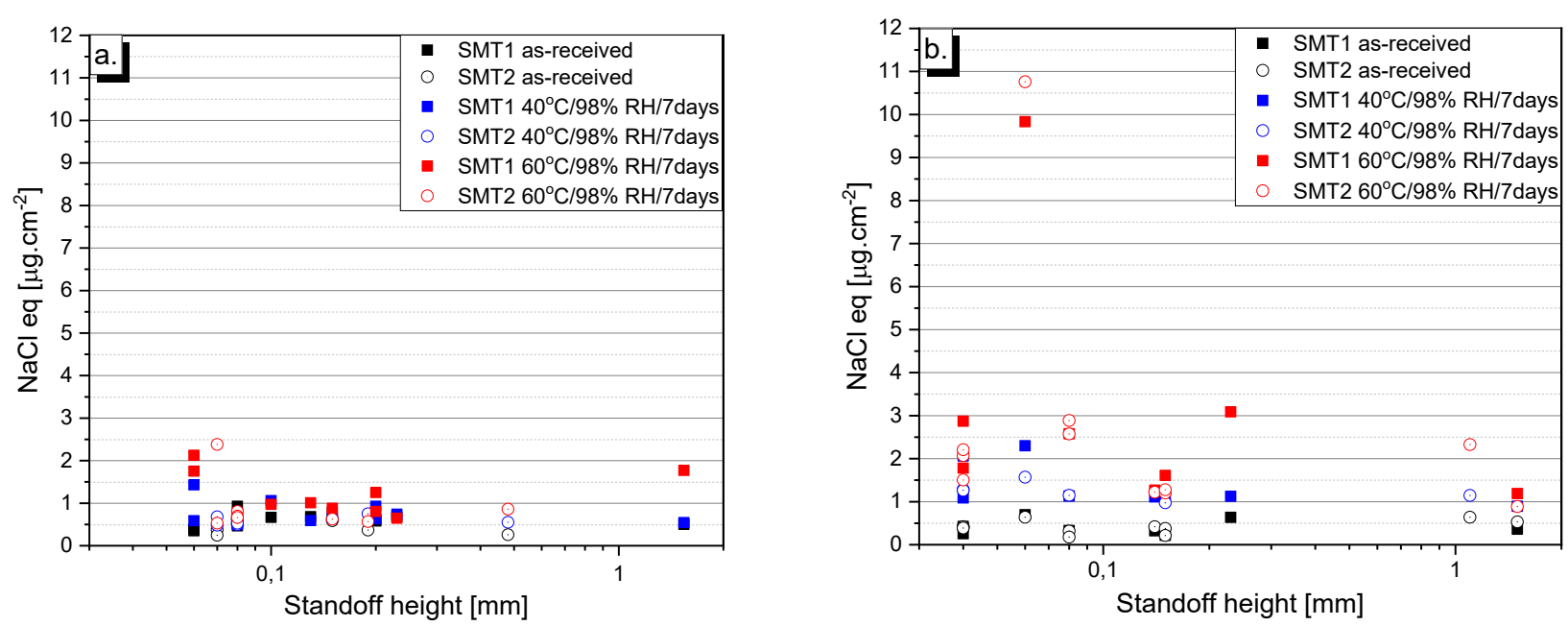

Fig. 6. $\mathrm{NaCl}$ equivalent concentration in function of the standoff height of the SMDs of the PCBAs from a) manufacturer 1 and b) manufacturer 3.

3) Electrical testing on SIR and dummy component test PCBs The EIS measurements were performed in order to assess the residue-water vapour interaction. The EIS results express the resistive and capacitive character of the water layer forming in between the conducting lines and solder pads under different frequency regimes. Change in impedance over frequency shows the change of resistive and capacitive properties of the residue as it absorbs moisture and connects between conduction lines. Fig. 7 and 8 show the impedance results (Bode plots) of the test PCBs after exposure to $60^{\circ} \mathrm{C} / 98 \% \mathrm{RH}$ for various length of time.

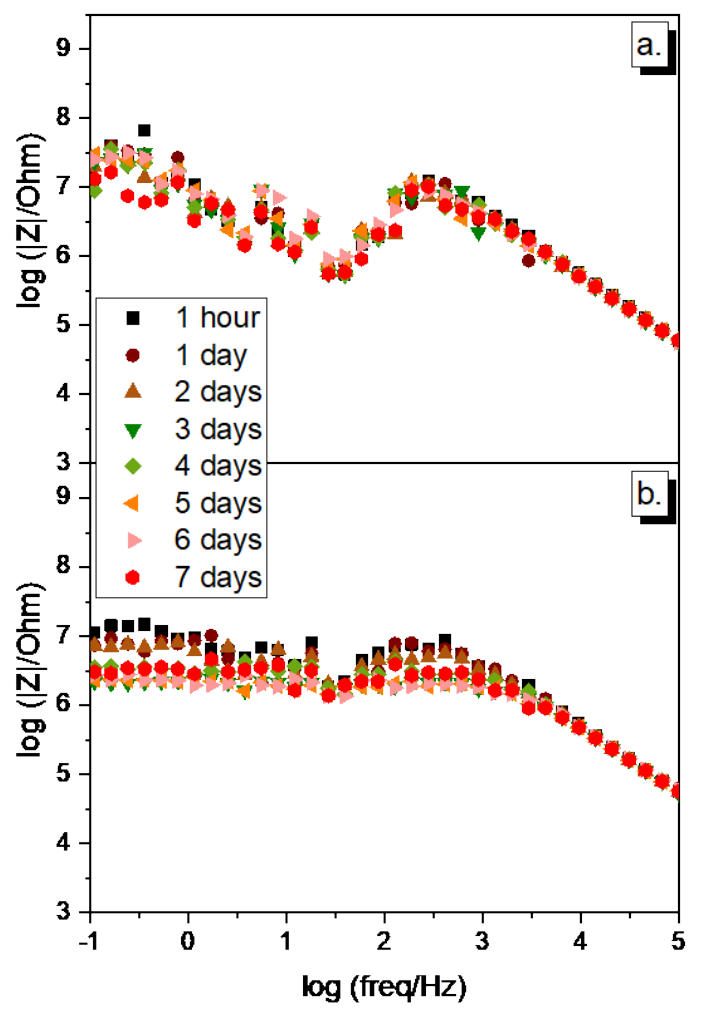

Fig. 7. Impedance spectra on SIR test PCBs reflowed with a) SPa and b) SPb.
Overall the EIS results show that the impedance over frequency did not change significantly upon humidity exposure for the test PCBs soldered with SPa (Fig. 7.a and 8.a). On the other hand, a decrease of the impedance values, especially at the low frequencies, is observed after exposure to humidity of $\mathrm{SPb}$ test PCBs (Fig. 7.b and 8.b). For open SIR test PCB, one decade of the decrease in impedance was observed over 7 days of humidity exposure, while for dummy component test PCB, impedance drop was more pronounced with a magnitude of about two decades.

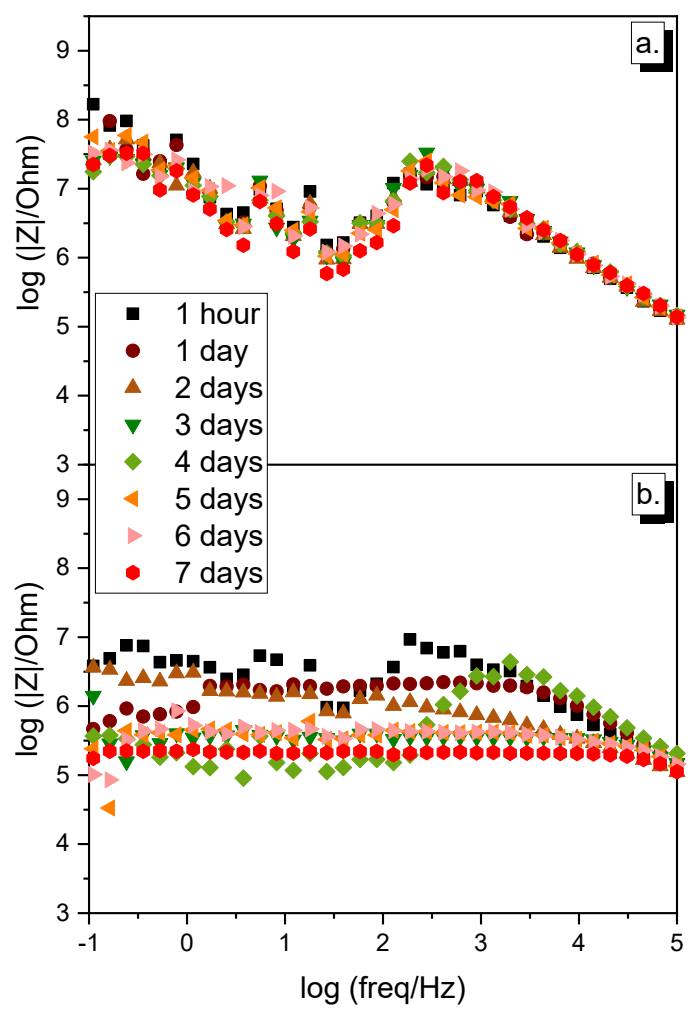

Fig. 8. Impedance spectra on dummy component test PCBs reflowed with a) $\mathrm{SPa}$ and b) $\mathrm{SPb}$. 


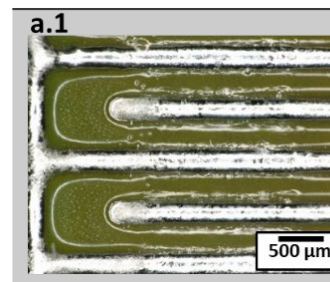

b.1

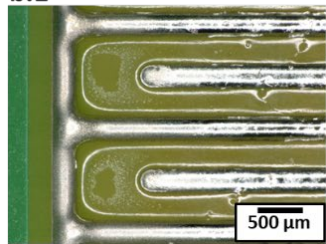

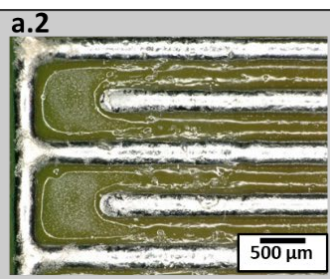

b.2

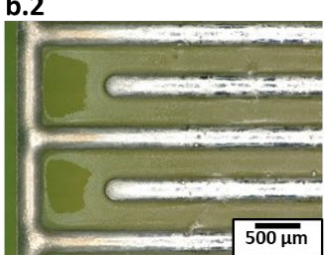

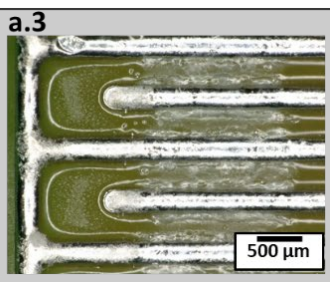

b.3

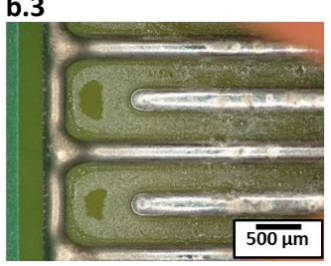

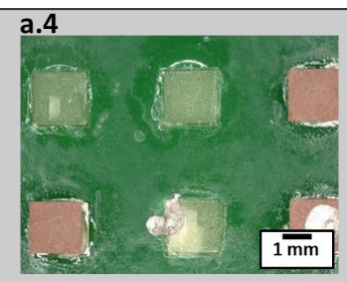

b.4

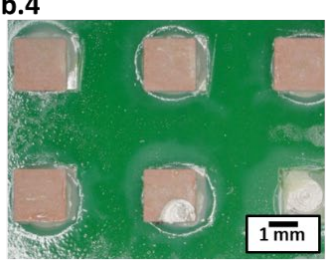

Fig. 9. OM pictures of test PCBs reflowed with a) SPa and b) SPb, (1) - SIR test PCBs prior exposure, and after exposure to (2) - 40 ${ }^{\circ} \mathrm{C} / 98 \% \mathrm{RH} / 7 \mathrm{days}$, and (3) $-60^{\circ} \mathrm{C} / 98 \% \mathrm{RH} / 7$ days, and (4) - disassembled dummy component test PCBs after exposure to $60^{\circ} \mathrm{C} / 98 \% \mathrm{RH} / 7$ days.

Fig. 9 shows the OM pictures after the soldering process and after exposure to humidity, of the SIR and the dissembled dummy component test PCBs. The same smooth morphology of the SPa residues (Fig. 9.a.1) than on actual PCBAs from manufacturer 1 can be observed. Upon humidity exposure, the residues become more whitish (Fig. 9.a.2 and a.3). SPb residues show more cracks upon humidity exposure (Fig. 9.b.2 and b.3), and the residues have spread between the conductive lines of the SIR. The series 4 of Fig. 9 show pictures of the dissembled dummy component test PCBs, after exposure to $60^{\circ} \mathrm{C} / 98 \% \mathrm{RH} / 7$ days. Higher spreading of $\mathrm{SPb}$ residues (series b) in comparison to SPa (series a) can be observed. The spreading of the $\mathrm{SPb}$ residues bridged the solder pads.

\section{DISCUSSION}

Previous studies [5-6;23] have shown that reflow soldering process results in low amount of residues left on PCBA surfaces. Since the reflow residues are trapped around the legs and/or under the components, even small amounts can create problem under humidity exposure due to localization of the residue. However, the level of cleanliness of the reflowed PCBAs surfaces is dependent on the composition of the SP (mainly its activators type and amount), the design of the PCBAs, and the soldering operation profiles. The nature of the residue is usually in a concealed form with active components embedded within the resin formed as a film. It has been reported that this residue film over exposure to humidity changes in morphology, leading to release of acidic compounds causing corrosion reliability issues [6-7]. Together with the climatic exposure conditions during service life, it determines the humidity robustness of electronic systems. Previous studies $[6 ; 8 ; 10 ; 18 ; 24]$ have shown that these residues are hygroscopic and of corrosive nature. Upon humidity exposure and water absorption from the residues, a conductive water layer can form between two electrical pads [8] leading to intermittent malfunction of the system.

\section{Morphology of the solder paste residue on PCBAs}

While the activator components from the SP formulation are concealed within or underneath the film-former layer of the residues after the soldering process [6-7] (confirmed by similar low levels of conductivity for all as-received PCBAs), the amount of activator and the robustness of the film former layer barrier are dependent on the solder flux chemistry and soldering profile. Morphology changes shown in Fig. 2 and 3 show that upon humidity exposure, SPa residues did not spread around the soldering pads, and no visible cracks were observed. However, $\mathrm{SPb}$ residues spread on the PCBAs surface, connecting adjacent electrical pads, and its appearance changes, with apparition of cracks and blisters.

Contamination level and related conductivity of residues from PCBAs

The PCBAs from the manufacturer 1, using SPa, exhibited lower contamination levels with less active residue. Even upon an exposure to $60^{\circ} \mathrm{C} / 98 \% \mathrm{RH} / 7$ days, the localized $\mathrm{NaCl}$ equivalent concentrations remained low. On the other hand, the localized contamination levels on the PCBAs from manufacturers 2 and 3, using $\mathrm{SPb}$, are much higher. The conductivity of the localized extracted solutions increases upon humidity exposure, and reaches very high values for the PCBAs of manufacturer 3, after exposure to $60^{\circ} \mathrm{C} / 98 \% \mathrm{RH} / 7$ days. Although the difference between manufacturers 2 and 3 highlights the influence of PCBA design and soldering profile differences, overall boards soldered using $\mathrm{SPb}$ show higher release of ionic residues after exposure to humidity. The morphological changes and appearance of cracks upon humidity exposure (observed by $\mathrm{OM}$ and SEM) can be correlated to the release of the acidic compound (activator), and this has increased the conductivity of localized areas on the PCBAs surface [25].

Effect of number of solder passes on residue

The analysis of the PCBAs soldered with additional reflow step operations (up to 9 reflow operations) showed that additional passes through high temperature has slightly reduced the contamination levels on the PCBAs. The activator has degraded and decomposed [10] upon each additional reflow profile, leading to lower the surface conductivity of the PCBAs. Effect of standoff height of component on residue

In the reflow process, the SP is directly applied on the SMD footprint areas using a stencil printing. The SP residue is then locally found around the legs and under the SMD. SP located below low standoff height components may not be exposed to the correct reflow temperature profile [26]. Exposure to lower 
peak temperature can cause incomplete soldering, and incomplete degradation of the activator compounds [10;27]. Low standoff height may also make the activation and evaporation of the flux difficult due to narrow gap. The flux outgassing/drying is getting very difficult due to poor venting channels [28]. This leads to higher amount of ionic contents in the residues. The investigation shows that the standoff height has also a direct impact on the interaction of the residue with humidity. The conductivity of the residues trapped under SMD with lower standoff height $(<100 \mu \mathrm{m})$ increased more upon humidity exposure. This suggests that this gap becomes a prone area for water absorption and release of acidic compounds from the trapped residues.

\section{Hygroscopicity of flux solder pastes}

The different water absorption properties of the SP residues are due to the different formulation (chemical nature and concentration) of the flux medium (film-former, solvent, activator, etc.). Water absorption characterization of the liquid part of the SP have shown that $\mathrm{SPb}$ can absorb up to 5 times more water than $\mathrm{SPa}$. The higher hygroscopicity of $\mathrm{SPb}$ residues increases the absorption of moisture from the surroundings while exposed to humid conditions, therefore resulting in higher thickness of the water film [20].

Impedance spectroscopy analysis of solder paste using test $\underline{P C B S}$

Upon high temperature and high humidity exposure, a release of the acidic compounds from the resin part takes place. Water absorption of the hygroscopic acid components leads to the formation of a water layer onto the surface of the test PCB. Some of the acid dissolves and dissociates to form an ionic conduction pathway. The dependence of the impedance on the characteristics of the SP residues and related electrolyte layer formation is more pronounced at lower frequencies [8-9].

EIS results show that the impedance $Z$ values of the SIR test $\mathrm{PCB}$ reflowed with $\mathrm{SPb}$ decreased after each day of humidity exposure to $60^{\circ} \mathrm{C} / 98 \% \mathrm{RH}$. This means that a thicker water layer has formed on this PCB, and the dissolution of the hygroscopic compounds of the residues into the formed water layer has decreased further the impedance values at low frequencies.

The concealed paste testing using the dummy component test PCB showed a drastic decrease of impedance upon humidity exposure for the test $\mathrm{PCB}$ soldered with $\mathrm{SPb}$. In this case, the gap of $1 \mathrm{~mm}$ between the two PCBs, intended to simulate the standoff height of SMD, may have created an occluded area prone to water absorption from the residues for water layer build up. Therefore, the impedance values have decreased drastically upon moisture exposure, compared to open SIR test PCB (Fig.7 and 8. b). OM pictures showed that the spreading of the $\mathrm{SPa}$ residues was less (Fig. 9.a.4), limiting the electrical connection between the solder pads. Therefore, the impedance values have not changed upon humidity exposure [29].

\section{CONCLUSION}

This investigation illustrated the contamination issues on actual manufactured PCBAs resulting from the use of reflow solder flux and the connection with the soldering operation steps, the standoff height of the SMD, the SP formulation and the exposure to humidity.

1. While solder paste residues conductivity was very low on all as-received PCBAs, humidity exposure has changed the morphology of the residues and increases its conductivity. The residue has spread in between the solder pads of the SMD, interconnecting them. Cracking of the film-former has allowed the release of the activators, which are ionic in nature.

2. The solder flux of SPb contains a higher amount of solid content, and the residue was more hygroscopic than $\mathrm{SPa}$. This led to higher spreading of the residues $\mathrm{SPb}$ upon humidity exposure and higher conductivity values. These two characteristics are the main factors for higher drop of impedance during the electrochemical testing, due to higher thickness of the formed electrolyte upon humidity exposure.

3. Low standoff height of SMD may prevent the correct activation of the flux leading to higher levels of activators in the residues. It is also a prone area for liquid water buildup absorbed by the trapped residues.

4. Increase number of soldering operation steps enhances the decomposition/evaporation of the flux components, and therefore decreases the conductivity level of the residues.

\section{ACKNOWLEDGMENT}

The research reported here has been conducted as part of the CELCORR/CreCon consortium (www.celcorr.com). Authors would like to acknowledge the consortium partners for funding support and all the help received during the program run.

\section{REFERENCES}

[1] X. Gui, Z. Zhang, L. Xu, and S. Liu, "On reflow soldering process and reflow profile," proceeding in 13th Int. Conf. Electron. Packag. Technol. High Density Packag. (ICEPTHDP 2012), pp. 866-871, 2012.

[2] P. Biocca, "Optimizing lead-free reflow processes," SMT Surf. Mt. Technol. Mag., vol. 19, no. 2, pp. 76-80, 2005.

[3] F. V. Barbosa, J. C. F. Teixeira, S. F. C. F. Teixeira, R. A. M. M. Lima, D. F. Soares, and D. M. D. Pinho, "Rheology of F620 solder paste and flux," Solder. Surf. Mt. Technol., vol. 31, no. 2, pp. 125-132, 2019.

[4] M. S. Jellesen, M. Dutta, V. Verdingovas, and R. Ambat, "Detection of acid release from reflow solder flux residues using localized test methods," proceeding in 4th European corrosion congress (Eurocorr), pp. 1-10, 2012.

[5] H. Conseil, M. S. Jellesen, and R. Ambat, "Contamination profile on typical printed circuit board assemblies vs soldering process," Solder. Surf. Mt. Technol., vol. 26, no. 4, pp. 194-202, 2014.

[6] K. Piotrowska, S. Lagana, M. S. Jellesen, and R. Ambat, "Impact of process-related flux contamination on the electronics reliability issues under detrimental climatic conditions," in 25th SMTA Pan Pacific Microelectronics Symposium, pp. 1-7, 2019.

[7] K. Piotrowska, F. Li, and R. Ambat, "Transformation of reflow solder flux residue under humid conditions," Microelectron. Reliab., vol. 123, no. May, p. 114195, 2021.

[8] V. Verdingovas, M. S. Jellesen, and R. Ambat, "Relative effect of solder flux chemistry on the humidity related failures in electronics," Solder. Surf. Mt. Technol., vol. 27, no. 4, pp. 146-156, 2015. 
[9] V. Verdingovas, M. S. Jellesen, and R. Ambat, "Solder Flux Residues and Humidity-Related Failures in Electronics: Relative Effects of Weak Organic Acids Used in No-Clean Flux Systems," J. Electron. Mater., vol. 44, no. 4, pp. 1116 1127,2015

[10] H. Conseil, V. Verdingovas, M. S. Jellesen, and R. Ambat, "Decomposition of no-clean solder flux systems and their effects on the corrosion reliability of electronics," J. Mater. Sci. Mater. Electron., vol. 27, no. 1, pp. 23-32, 2016.

[11] K. Piotrowska, M. Grzelak, and R. Ambat, "No-Clean Solder Flux Chemistry and Temperature Effects on HumidityRelated Reliability of Electronics," J. Electron. Mater., vol. 48, no. 2, pp. 1207-1222, 2019.

[12] B. A. Smith and L. J. Turbini, "Characterizing the weak organic acids used in low solids fluxes," J. Electron. Mater., vol. 28, no. 11, pp. 1299-1306, 1999.

[13] L. J. Turbini, G. B. Freeman, M. H. Smith, J. D. Finney, R. D. Boswell, and J. F. Lane, "Characterising the Corrosion Properties of Flux Residues: Part 1: Test Method Development and Failure Mode Identification," Solder. Surf. Mt. Technol., vol. 3, no. 2, pp. 24-31, 1991.

[14] J. E. Sohn and U. Ray, "Weak Organic Acids and Surface Insulation Resistance," Circuit World, vol. 21, no. 4, pp. 22 26, 1995.

[15] C. Hunt and L. Zou, "The impact of temperature and humidity conditions on surface insulation resistance values for various fluxes," Solder. Surf. Mt. Technol., vol. 11, no. 1, pp. 36-43, 1999.

[16] S. Zhan, M. H. Azarian, and M. Pecht, "Reliability of printed circuit boards processed using no-clean flux technology in temperature-humidity-bias conditions," IEEE Trans. Device Mater. Reliab., vol. 8, no. 2, pp. 426-434, 2008.

[17] R. Ambat et al., "Solder flux residues and electrochemical migration failures of electronic devices," proceeding in 7th european corrosion congress (Eurocorr), pp. 6-10, 2015.

[18] K. Piotrowska, M. S. Jellesen, and R. Ambat, "Thermal decomposition of solder flux activators under simulated wave soldering conditions," Solder. Surf. Mt. Technol., vol. 29, no. 3, pp. 133-143, 2017.

[19] K. Piotrowska, V. Verdingovas, and R. Ambat, "Humidityrelated failures in electronics: effect of binary mixtures of weak organic acid activators," J. Mater. Sci. Mater. Electron., vol. 29, no. 20, pp. 17834-17852, 2018.

[20] K. Piotrowska, R. Ud Din, F. B. Grumsen, M. S. Jellesen, and R. Ambat, "Parametric Study of Solder Flux Hygroscopicity: Impact of Weak Organic Acids on Water Layer Formation and Corrosion of Electronics," J. Electron. Mater., vol. 47, no. 7, pp. 4190-4207, 2018.

[21] S. Wakeel, A. S. M. A. Haseeb, M. A. Afifi, S. Bingol, and K. L. Hoon, "Constituents and performance of no-clean flux for electronic solder," Microelectron. Reliab., vol. 123, no. May, p. 114177, 2021.

[22] L. Buenaflor, S. L. Dal, and I. Estinozo, "Thermal profiling to overcome flux residue formation in a no-clean solder paste for lead-free surface mount technology," proceeding in 9th Electron. Packag. Technol. Conf. (EPTC), pp. 1-4, 2007.

[23] R. Ambat and K. Piotrowska, "PCBA cleanliness as a means to improve humidity robustness of electronics," proceeding in SMTA International conference, pp. 1-4, 2019.

[24] M. S. Jellesen, D. Minzari, U. Rathinavelu, P. Møller, and R. Ambat, "Corrosion failure due to flux residues in an electronic add-on device," Eng. Fail. Anal., vol. 17, no. 6, pp. 1263-1272, 2010.

[25] K. H. Lee, R. Jukna, J. Altpeter, and K. Doss, "Comparison of ROSE, C3/IC, and SIR as an effective cleanliness verification test for post soldered PCBA," Solder. Surf. Mt. Technol., vol. 23, no. 2, pp. 85-90, 2011.

[26] B. Tolla, J. Allen, K. Loomis, D. Jean and M. Bixenman, "No-Clean Flux Activity under Low Standoff Components," proceeding in SMTA-IPC High-Reliability Cleaning and Conformal Coating Conference, pp. 83-116, 2015.

[27] K. Piotrowska, F. Li, and R. Ambat, "Thermal decomposition of binary mixtures of organic activators used in no-clean fluxes and impact on PCBA corrosion reliability," Solder. Surf. Mt. Technol., vol. 32, no. 2, pp. $93-$ $103,2019$.

[28] F. Chen and N-C. Lee', "The risk and solution for no-clean flux not fully dried under component terminations," proceeding in $16^{\text {th }}$ International Conference on Electronic Packaging Technology, pp. 387-395, 2015.

[29] H. Conseil-Gudla, M. S. Jellesen, and R. Ambat, "Printed Circuit Board Surface Finish and Effects of Chloride Contamination, Electric Field, and Humidity on Corrosion Reliability," J. Electron. Mater., vol. 46, no. 2, pp. 817-825, 2017.

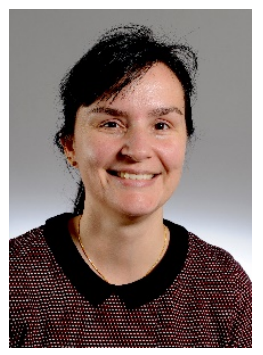

Helene Conseil-Gudla received the M.Sc. degree in Materials Science from the engineering school Polytech'Lille, Lille, France, and the Ph.D. student at the Department of Mechanical Engineering, Technical University of Denmark (DTU), Lyngby, Denmark. She is currently a Post Doc Researcher with the Department of Mechanical Engineering, Technical University of Denmark, Lyngby, Denmark. Her current research interests include proactive-design-and-monitoring strategy of electronic products for high humidity robustness, and reliability of electronic packaging materials.

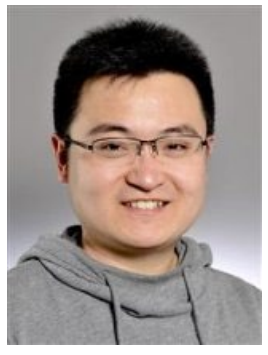

Feng $\mathbf{L i}$ received the MSc and $\mathrm{PhD}$ degree at Department of Mechanical Engineering, Technical University of Denmark (DTU), Lyngby, Denmark. He is currently a Post Doc Researcher with the Department of Mechanical Engineering, Technical University of Denmark, Lyngby, Denmark. His research activities focused on humidity and corrosion reliability of electronics, including optimization of flux formulation, optimization of reliability testing methods and material selection.

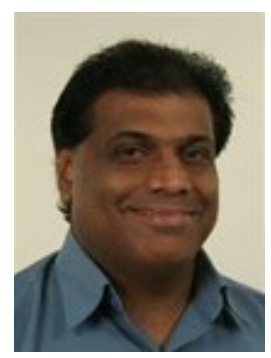

Rajan Ambat received the Ph.D. degree from the Indian Institute of Science, Bangalore, India. $\mathrm{He}$ was an EPSRC Research Fellow with the University of Birmingham, Birmingham, U.K., where worked in collaboration with Airbus, London, U.K., BAE systems, London, Alcan International, Slough, U.K., and Jaguar, London. He is currently a Professor with the Department of Mechanical Engineering, Technical University of Denmark (DTU), Lyngby, Denmark, and the Manager of the Centre for Electronic Corrosion and Consortium for Climatically Reliable Electronics, Lyngby, Denmark. He teaches courses on materials in advanced applications and products, including materials on printed circuit board (PCB) assembly, PCB manufacturing, and corrosion issues.

His current research interests include corrosion reliability of electronic devices, materials for electrical contacts, highresolution electrochemical measurements and test methods for electronic corrosion, intelligent nano-coatings on aluminium, and biomechanics. 